\title{
Perbedaan Latihan Nordic Walking dan Brisk Walking Terhadap Perubahan Sirkulasi Arteri Kaki pada Penderita PAD
}

\author{
Iis noventi, Siti Damawiyah, Siti Maimunah
}

Universitas Nahdlatul Ulama, Fakultas Keperawatan dan Kebidanan, Program

Studi S1 Keperawatan, J1. Smea No.57, Wonokromo, Kec. Wonokromo, Kota

Surabaya, Jawa Timur

Email: iisnoventi@unusa.ac.id

$\begin{array}{ll}\text { Diterima } & : \text { 29 September } 2020 \\ \text { Disetujui } & : 26 \text { November } 2020 \\ \text { Dipublikasikan } & : \text { 10 Desember } 2020\end{array}$

\begin{abstract}
Abstrak
Latar Belakang dan Tujuan: Peripheral Arterial Disease (PAD) adalah salah satu komplikasi yang sangat sering dari makrovaskular. PAD merupakan manifestasi dari aterosklerosis yang ditandai oleh penyakit penyumbatan atherosklerosis pada ekstermitas bawah. Denyut nadi kaki dipengaruhi juga oleh aktivitas fisik. Tujuan dari penelitian ini untuk mengetahui adanya perbedaan latihan Nordic Walking dan Brisk Walking terhadap perubahan sirkulasi arteri kaki (dorsalis pedis) pada penderita PAD.

Metode: Metode penelitian ini adalah pretest-posttest control group design dan teknik acak sederhana digunakan untuk mengumpulkan subjek. Sebanyak 40 subjek dari warga RW 03 Karang Rejo Dua Kelurahan Wonokromo, terbagi dalam Kelompok Perlakuan I dengan jumlah 20 orang dan Kelompok Perlakuan II berjumlah 20 orang. Denyut nadi kaki diukur menggunakan Simple Handheld Vascular Doppler Ultrasound Probe dan tensimeter.

Hasil: Hasil penelitian menunjukkan bahwa pada Kelompok Perlakuan I terdapat perbedaan bermakna pada denyut nadi kaki dibandingkan pada Kelompok Perlakuan II $(\mathrm{p}=0,000)$.

Simpulan dan Implikasi: Latihan Nordic Walking dapat menimbulkan perubahan denyut nadi kaki lebih besar dibandingkan latihan Brisk Walking. Dengan demikian nordic walking lebih disarankan diberikan pada pasien PAD untuk meningkatkan sirkulasi arteri kaki.
\end{abstract}

Kata Kunci: Brisk Walking; Nordic Walking; PAD; Sirkulasi nadi kaki

Sitasi: Noventi I, Damawiyah S \& Maimunah S. (2020). Perbedaan latihan nordic walking dan brisk walking terhadap perubahan sirkulasi arteri kaki pada penderita PAD. The Indonesian Journal of Health Science. 12(2), 147-157

Copyright: (C) 2020 Noventi et al. This is an open-access article distributed under the terms of the Creative Commons Attribution-NonCommercial 4.0 International License, which permits unrestricted use, distribution, and reproduction in any medium, provided the original author and source are credited.

Diterbitkan Oleh: Universitas Muhammadiyah Jember

ISSN (Print): 2087-5053

ISSN (Online): 2476-9614 


\begin{abstract}
Background and Aim: Peripheral Arterial Disease (PAD) is a prevalent macrovascular complication PAD is a manifestation of atherosclerosis which is characterized by atherosclerotic obstruction of the lower extremities. The pulse rate of the legs is also affected by physical activity. The purpose of this study was to determine the differences in Nordic Walking and Brisk Walking exercises on changes in the dorsalis pedis artery circulation in patients with PAD.

Methods: This method of this study is a pretest-posttest control group design and a simple random technique was used to collect the subjects. A total of 40 subjects from residents of RW 03 Karang Rejo Dua, Wonokromo Village, were divided into treatment group I with 20 participants and the same as in the treatment Group II. The handheld Doppler ultrasound was used to measure the dorsalis pedis pulse. Results: The results showed that there was a significant difference in the dorsalis pedis pulse in the treatment group I compared to the treatment group II ( $\mathrm{p}=$ 0.000).

Conclusion: Nordic Walking exercises induce-the dorsalis pedis pulse changes than Brisk Walking exercises. Therefore, nordic walking is recommended to be given to patients with PAD to improve the arterial circulation of the legs.
\end{abstract}

Keywords: Brisk Walking; Leg pulse circulatio; Nordic Walking; PAD

\section{PENDAHULUAN}

Penyakit Arteri adalah penyempitan arteri yang tidak normal selain yang menyuplai jantung atau otak. Penyakit arteri perifer paling sering menyerang kaki, tetapi arteri lain juga sering terlibat seperti di lengan, leher atau ginjal ( Shantulli, 2018). Gejala klasiknya adalah nyeri tungkai saat berjalan yang hilang dengan istirahat, yang dikenal sebagai klaudikasio intermiten( Violi, 2012). Gejala lainnya seperti bisul kulit, kulit kebiruan, kulit dingin, atau pertumbuhan dan rambut yang tidak normal di kaki yang terkena. Sebagian besar PAD tidak bergejala, kurang dari $50 \%$ dengan gejala khas yakni $1 / 3$ nya dengan klaudikasio (nyeri, kram pada kaki saat berjalan yang membaik dengan istirahat) dan sisanya dengan gejala yang lebih yang dikenal dengan istilah critical limb ischemi (Gao, 2009). Faktor resiko terbesar PAD adalah merokok, diabetes, tekanan darah tinggi, masalah ginjal, dan kolesterol darah tinggi (Fowkes, 2013).

Mekanisme yang mendasari penyakit arteri perifer yang paling umum adalah aterosklerosis, terutama pada individu berusia di atas 40 tahun (Gerhard, 2017). MekanismeDenyutan pada tumit memang dapat terjadidan merupakan suatu fenomena fisiologis yang disebabkan oleh adanya pembuluh darah nadi yang bernama Arteri Dorsalis Pedis.Lokasi dari pembuluh darah tersebutadalah di sekitar tumit dan memiliki sifat berdenyut.Pada umumnya denyutannya bersamaan dengan denyutan jantung dan dapat dicek sebagai penanda apakah aliran darah ke ekstremitas bawah telah adekuat atau tidak.Oleh karena pembuluh nadi tersebut berada cukup dalam di bawah lapisan lemak, maka orang yang kurus cenderung lebih teraba denyutannya lain termasuk kejang arteri, pembekuan darah, 
trauma, dysplasia fibromuskular dan vaskulitis. Denyutan pada tumit memang dapat terjadidan merupakan suatu fenomena fisiologis yang disebabkan oleh adanya pembuluh darah nadi yang bernama Arteri Dorsalis Pedis.Lokasi dari pembuluh darah tersebutadalah di sekitar tumit dan memiliki sifat berdenyut.Pada umumnya denyutannya bersamaan dengan denyutan jantung dan dapat dicek sebagai penanda apakah aliran darah ke ekstremitas bawah telah adekuat atau tidak.Oleh karena pembuluh nadi tersebut berada cukup dalam di bawah lapisan lemak, maka orang yang kurus cenderung lebih teraba denyutannya. Indikator penurunan perfusi ke daerah tungkai dapat diukur melalui ABPI. ABPI adalah rasio dari tekanan darah sistolik yang diukur di area kaki dan yang diukur di arteri brachial dan digunakan untuk mengetahui adanya PAD salah satunya disebabkan oleh penyaki DM (Aboyans et al., 2012). Index tekanan ankle-brachial (ABPI) adalah rasio tekanan darah di pergelangan kaki dengan tekanan darah di lengan atas (brachium). Di bandingkan dengan lengan, tekanan darah yang lebih rendah di kaki menujukkan arteri yang tersumbat karena penyakit arteri perifer ( PAD). ABPI di hitung dengan membagi tekanan darah sistolik di pergelangan kaki dengan tekanan darah sistolik di lengan(Al-Qaisi, 2009).

ABPI adalah rasio tekanan pergelangan kaki tertinggi terhadap arteri brakialis ABPI, apabila hasilnya termasuk > 1,0 dianggap normal (bebas dari PAD yang signifikan), sedangkan yang lebih kecil dari 0,9 menunjukkan penyakit arteri (Rooke, 2011). Nilai ABPI 1,3 atau lebih besar juga dianggap abnormal, dan menunjukkan kalsifikasi dinding arteri dan pembuluh darah yang tidak dapat di mampatkan, yang mencerminkan penyakit vascular perifer yang parah.

Manfaat olahraga terutama yang dapat memperlancar sirkulasi darah dan oksigen dalam tubuh misalnya lari, bersepeda, jalan cepat dan berenang (Lubis, 2009). Olah raga jalan secara teratur akan meningkatkan jarak tempuh (Ratcliff, 2007). Pencapaian kapasitas fungsional seperti denyut nadi kaki yang optimal dapat ditindaklanjuti dengan melakukan aktivitas fisik dalam waktu lama dan berkesinambungan (Sandi, 2016). Aktivitas fisik dengan jenis aerobik, salah satunya berjalan, diketahui dapat mengurangi aktivasi sistem saraf simpatis sementara meningkatkan aktivasi sistem saraf parasimpatis yang menghasilkan penurunan denyut nadi istirahat ( Kang, 2016).

\section{Latihan Nordic Walking} diketahui memiliki pengaruh positif terhadap tiga aspek, yaitu aspek fisik, biomekanik dan program kebugaran, dimana pada aspek fisik salah satunya yaitu frekuensi denyut nadi (Pérez, Martínez, Aparicio,2014).

Nordic Walking menghasilkan peningkatan yang signifikan dalam penggunaan oksigen ( $23 \%$ ) dan pengeluaran kalori (22\%) dibandingkan dengan jalan kaki biasa, tanpa peningkatan aktivitas yang dirasakan (Norgren, 2007).Nordic Walking juga telah terbukti meningkatkan kebugaran kardiovaskular pada pasien dengan klaudikasio intermitten ( Fowkes, Housley, Cawood, et.al. 1991). Tipe latihan berjalan, seperti Nordic Walking (NW) yang berjalan menggunakan dua tongkat, dapat 
menurunkan denyut nadi istirahat secara bermakna pada kelompok lansia perempuan (Mikalački, 2011).Menurut penelitian sebelumnya, berjalan Nordic meningkatkan kecepatan berjalan dan metabolisme kardiovaskular (Churchetal., 2002; Porcarietal., 1997). Sebuah studi yang lebih baru menemukanbahwa ketika berjalan di Nordicdilakukan dengan kecepatan yang lebih lambat daripada berjalan kakikonvensional tanpaNordic, ini menghasilkan detak jantung yang lebih tinggi dan konsumsi oksigen yang lebih tinggi (Schifferetal., 2006). Jalan Nordic juga telah digunakan untuk rehabilitasi pada individu dengan klaudikasiointermiten (Oakleyetal., 2008).

Brisk Walking Exercise sebagai salah satu bentuk latihan aerobic merupakan bentuk latihan aktivitas sedang dengan menggunakan tehnik jalan cepat selama 20-30 menit dengan rerata kecepatan 4-6 km/jam. Selain itu juga latihan berjalan cepat menurunkan fungsional yang lebih cepat dan menurunkan lebih besar dalam kepadatan otot betis, pada pasien dengan PAD. Berdasarkan uraian tersebut, peneliti akanmelakukan penelitian mengenai perbedaan latihan Nordic Walking dan Brisk Walking terhadap perubahan denyut nadi kaki pada pasien degan PAD.

\section{METODE PENELITIAN}

Penelitian ini menggunakan metode pretest-posttest control group design. Pengelompokan subjek dilakukan secara acak sederhana.Penelitian ini berlangsung dari bulan Juni hingga Agustus 2020 dan telah mendapat persetujuan dari Komite Etik Penelitian.
Subjek diperoleh dari jumlah populasi 150 orang yang terdaftar dalam Posyandu Lansia di RW 03 Karang Rejo Dua maupun warga yang tidak tergabung dalam Posyandu Lansia, Kelurahan Wonokromo, Kota Surabaya. Kriteria inklusi pada penelitian ini ialah berusia $\geq 30$ tahun yang memiliki index ABPI $\leq 0,90$ dan $>1.3$ atau sudah terdapat gejala Vascular calcification (VC), bersedia mengisi kuesioner dari Klaudikasio Edinburgh dan tidak memiliki gangguan keseimbangan. Kriteria ekslusi adalah subyek menderita iskemik di kaki, mempunyai gejala Frozen shoulder, memiliki penyakit arteri koroner yang tidak stabil, memiliki riwayat hipertensi, fraktur, mengkonsumsi alkohol, merokok, amputasi dan tidak bisa berjalan atau berhenti berolahraga karena nyeri lutut atau pinggul.

Subjek penelitian kemudian dibagi ke dalam Kelompok Perlakuan I (KP1) yang melakukan latihan Nordic Walking dan Brisk WalkingII (KP2). Subjek penelitian melakukan masing-masing perlakuan dengan frekuensi latihan 3 kali/perminggu selama 8 minggu dengan durasi minimal 60 menit per latihan. Pengukuran denyut nadi istirahat sebelum dan sesudah perlakuan pada penelitian ini menggunakan Simple Handheld Vascular Doppler Ultrasound Probe dan Tensimeter. dimana subjek penelitian duduk dengan tenang dan rileks selama 5 menit sebelumnya. Selama penelitian berlangsung tidak ada subjek penelitian yang drop out.

Langkah pertama subyek diberikan kuesioner dan wawancara dengan kuesioner Edinburgh untuk mengumpulkan informasi yang mencakup keluhan sakit/kram pada 
kaki ketika berjalan, berdiri/duduk, berjalan mendaki, dengan langkah teratur, posisi berdiri tegak dan subyek diberi gambar/skets untuk melokalisasi daerah yang sakit. Penilaian Intermitte Claudication/IC positif bila ditemukan semua jawabannya positif. Langkah kedua dilakukan pemeriksaan fisik : Inspeksi kaki dan palpasi denyut kaki perifer. Pada inspeksi diamati adanya tanda - tanda rubor, pucat, dan tidak adanya bulu kaki, distropia kuku ibu jari dan rasa dingin pada tungkai bawah, kulit kering fissure pada kulit.Langkah ketiga dilakukan pengukuran ABPI dengan menggunakan alat Simpel Handheld Vascular Doppler Ultrasound Probe Dan Tensimeter, subyek diposisikan berbaring selama 5-10 menit, lalu dipasang manset di kaki, tekanan manset dinaikkan hingga dopler tidak didengar lagi .Subyek diminta untuk tenang dan tidak bergerak selama pengukuran, gelombang dopler minimal 3 gelombang pulsasi prosedur yang sama di lakukan pada tungkai dan lengan. Setelah itu klasifikasi dari hasil yang diperoleh, bila hasilnya $>1,0$ atau $<1,3$ dikeluarkan dari subyek penelitian. Seluruh data yang didapat diolah menggunakan komputer. Karakteristik subjek dianalisis dengan uji statistik deskriptif. Distribusi nilai denyut nadi istirahat diuji dengan uji normalitas dan varian data homogen atau tidaknya dengan uji homogenitas, sedangkan hipotesis diuji dengan menggunakan uji parametrik.

\section{HASIL}

Data yang terkumpul dihitung dengan menggunakan software spss. Diketahui bahwa peningkatan rata rata dari ankle-brachial index setelah latian nordic walking masing-masing adalah 10,4 (Gambar 1). Rata - rata peningkatan dari anklebrachialindex setelah latihan brisk walking masing - masing adalah 0,65 (Gambar 2).Variasi dari anklebrachial Pressure index sebelum dan sesudah latihan Nordic walking dapat dilihat pada tabel 1 .

Gambar 1.Variasi dari ankle - brachial pressure index sebelum dan sesudah nordic walking

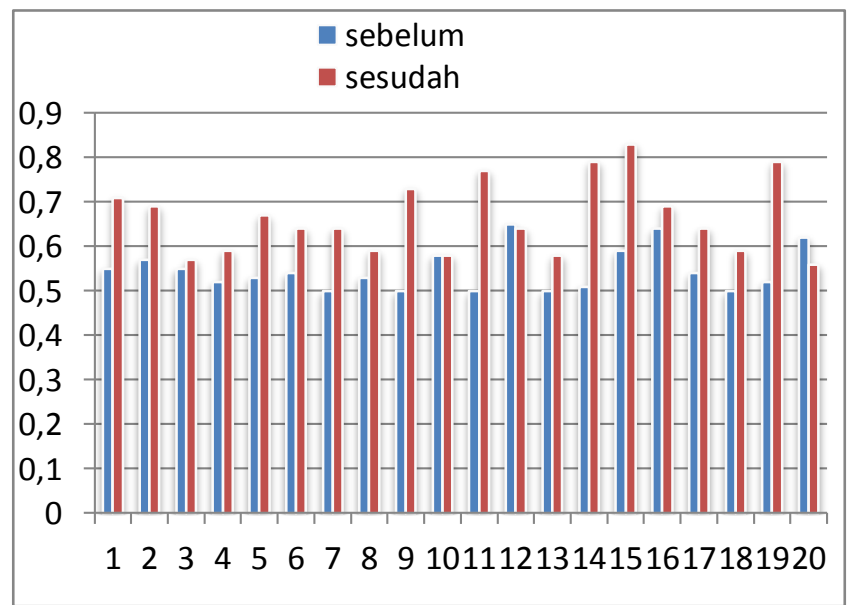


Gambar 2.Variasi dari ankle - brachial pressure index sebelum dan sesudah brisk walking

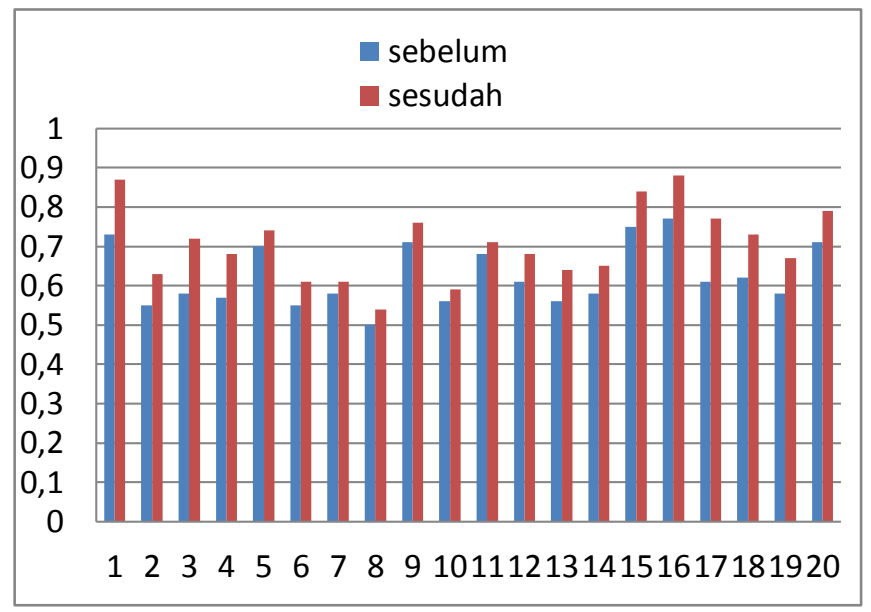

Tabel 3. Nilai rata-rata ABPI sebelum dan sesudah dilakukan Nordic Walking dan Brisk Walking

\begin{tabular}{ccccc}
\hline $\mathrm{N}$ & \multicolumn{2}{c}{ Brisk Walking } & \multicolumn{2}{c}{ Nordic Walking } \\
\hline & Pre & Post & Pre & Post \\
\hline 1 & 0.73 & 0.87 & 0.55 & 0.71 \\
2 & 0.55 & 0.63 & 0.57 & 0.69 \\
3 & 0.58 & 0.72 & 0.55 & 0.57 \\
4 & 0.57 & 0.68 & 0.52 & 0.59 \\
5 & 0.7 & 0.74 & 0.53 & 0.67 \\
6 & 0.55 & 0.61 & 0.54 & 0.64 \\
7 & 0.58 & 0.61 & 0.5 & 0.64 \\
8 & 0.5 & 0.54 & 0.53 & 0.59 \\
9 & 0.71 & 0.76 & 0.5 & 0.73 \\
10 & 0.56 & 0.59 & 0.58 & 0.58 \\
11 & 0.68 & 0.71 & 0.5 & 0.77 \\
12 & 0.61 & 0.68 & 0.65 & 0.64 \\
13 & 0.56 & 0.64 & 0.5 & 0.58 \\
14 & 0.58 & 0.65 & 0.51 & 0.79 \\
15 & 0.75 & 0.84 & 0.59 & 0.83 \\
16 & 0.77 & 0.88 & 0.64 & 0.69 \\
17 & 0.61 & 0.77 & 0.54 & 0.64 \\
18 & 0.62 & 0.73 & 0.5 & 0.59 \\
19 & 0.58 & 0.67 & 0.52 & 0.79 \\
20 & 0.71 & 0.79 & 0.62 & 0.56 \\
\hline & & & & \\
\hline Mean & 0.625 & 0.7055 & 0.547 & 0.6645 \\
\hline Standart Deviasi & 0.078707 & 0.09361 & 0.047362 & 0.083001 \\
\hline
\end{tabular}




\section{PEMBAHASAN}

Subjek pada penelitian ini berjumlah 40 orang berdasarkan kriteria yang telah ditentukan peneliti, melakukan masing-masing perlakuan selama 3 kali selama seminggu selama 8 minggu. Penelitian sebelumnya mengenai pengaruh latihan Nordic Walking dan latihan berjalan konvensional dengan kombinasi latihan lainnya dibandingkan dengan kelompok kontrol dapat meningkatkan fleksibilitas dan kekuatan tubuh bagian atas dan bawah, meningkatkan ketahanan kardiovaskuler (Nabuo, 2013).

Menurut sebuah studi oleh Collins dkk( 2003)., menunjukkan peningkatan toleransi latihan secara signifikan, responden juga mengalami nyeri klaudikasio yang lebih sedikit setelah latihan. Selain itu, responden mengalami peningkatan jarak tempuh dan kecepatan berjalan setelah berjalan dengan Nordic. Dalam penelitian ini, ditemukan tidak hanya mengurangi nyeri, meningkatkan jarak tempuh dan kecepatan berjalan tetapi juga peningkatan hasil pemeriksaan ABPI dengan perbedaan masing - masing 0,04 MHz.Perubahan denyut nadi kaki ini dapat diakibatkan karena terjadinya aktivitas kinesiologi berkelanjutan secara optimal dan mekanisme respon fisiologis dalam tubuh sehingga dapat memelihara dan meningkatkan kemampuan fungsional (Mikalački, 2011).Selama latihan berlangsung terjadi peningkatan bermakna dari aktivitas otot ekstremitas atas seperti otot biceps brachii, triceps, deltoid medius, dan latissimus dorsi.Latihan Nordic Walking juga dapat meningkatkan panjang langkah dan waktu pola berjalan selama heel contact hingga foot flat dikarenakan tongkat latihan turun bersamaan dengan pola heel contact, serta menurunkan waktu pola berjalan selama foot flat hingga heel off dikarenakan tongkat latihan menekan permukaan jalan sehingga pola heel off lebih cepat dilakukan selama melangkah (Shim, 2013).

Berjalan dengan Nordic

Menurut International Nordic walking Federation ( INWA), tehnik yang benar dalam menggunakan tongkat melibatkan posisi tongkat mundur selama berjalan, penggunaan tongkat secara aktif dan dinamis, dan tongkat sebagai pengontrolnya ada di pegangan dan tali. Penggunaan tongkat secara aktif menggerakkan tubuh bagian atas untuk mendorong tubuh ke depan selama berjalan (Pellegrini, Alexandre, Tartaruga, Zoppirolli. 2015). Penyerapan oksigen ( VO2), detak jantung (HR), dan konsentrasi laktat darah lebih meningkat ketika berjalan dengan Nordic walking. Pengeluaran energi pada kecepatan tertentu sekitar $20 \%$ lebih tinggi, dengan jumlah perbedaan tergantung pada faktor tehnis, jenis tiang dan jenis peralatan (Schiffer T, Knicker A, Hoffman U, Harwig B, Hollmann W, Struder HK, 2006).

Brisk Walking Exercise merupakan latihan aerobic yang sangat mudah dilakukan dengan berjalan dalam beberapa puluh menit sangat bermanfaat untuk mengendorkan ketegangan saraf, mengembalikan fungsi hormonal, dan menyelaraskan kembali neotransmitter yang bertugas untuk mengatur tekanan darah ( Lingga, 2012) Dalam penelitian kami, ditemukan tidak hanya mengendorkan ketegangan saraf, mengembalikan fungsi hormonal, 
dan menyelaraskan kembali neotransmitter yang bertugas untuk mengatur tekanan darah tetapi juga peningkatan hasil pemeriksaan ABPI dengan perbedaan rata-rata masing masing 0,02 $\mathrm{MHz}$.

Brisk walking adalah jenis latihan dengan berjalan kaki lebih cepat, meski tidak secepat berlari.Aturan kecepatan latihan ini adalah satu kilometer dalam 12 menit atau jarak 5 kilometer ditempuh dalam waktu satu jam. Brisk Walking Exercise merupakan latihan fisik yang mudah untuk diterapkan dan merupakan suatu kegiatan sederhana yang dapat dilakukan oleh setiap orang.Brisk walking exercise dapat dilakukan selama 5 kali dalam seminggu dan 30 menit sehari untuk pencapaian yang optimal (Kirstenpeters, 2014).Brisk walking exercise yang dilakukan selama 30 menit dalam sehari dapat membakar 90 hingga 200 kalori, memperkuat jantung dan paru-paru, meningkatkan kebugaran, membantu mengontrol berat badan, mengurangi kolesterol dan menurunkan tekanan darah (Robinson, 2014). Brisk walking exercise dapat menurunkan kolesterol, tekanan darah dan risiko terjadinya penyakit kardiovaskuler apabila diimbangi dengan pola makan yang baik (Lordan, 2015).

Hasil penelitian yang dilakukan oleh peneliti mengenai perbedaan latihan Nordic Walking dan Brisk Walking terhadap perubahan denyut nadikaki pada PAD, yaitu latihan Nordic Walking memiliki perbedaan yang bermakna pada denyut nadi kaki. Perubahan denyut nadi kaki sesudah perlakuan tersebut menunjukkan kondisi responden yang menjadi subjek penelitian ini tergolong baik dari segi fungsi sistem peredaran darah nya.
Pelaksanaan perlakuan selama 3 kali dalam seminggu selama 8 minggu ( 24 kali) dengan intensitas yang sama. Hasil penelitian mengungkapkan bahwa olah raga Nordic Walking dan Brisk Walkingmembantu PAD, tetapi intervensi Nordic Walking adalah yang paling efektif. Beberapa peneliti sebelumnya juga telah mengamati bahwa Nordic walking dapat meningkatkan kecepatan berjalan dan meningkatkan sistem kardiovaskuler dibuktikan dengan Heart Rate yang lebih tinggi dan peningkatan saturasi oksigen ( Fowkes, 1991). Meskipun terdapat peningkatan tenaga selama menggunakan tongkat Nordik, tetapi responden mengalami nyeri kaki yang lebih sedikit, ini menunjukkan bahwa Nordic Walkingbisa menjadi metode yang berguna untuk melancarkan aliran darah pada pasien PAD yang biasanya tidak bisa berjalan cepat dan jarak tempuh yang pendek. Dari pengalaman tersebut responden akan lebih meningkatkan jarak tempuh dari sebelumnya yang berdampak pada perubahan gaya hidup dan kebugaran.

Tingkat penurunan nyeri tungkai selama NPW disebabkan oleh penurunan stres beban tungkai bawah. Willson dkk. (2001) menunjukkan bahwa penggunaan tongkat nordik memungkinkan responden untuk berjalan dengan kecepatan lebih tinggi dibantu dengan tongkat yang menekan di permukaan tanah dan meningkatkan kekuatan otot selama gerakan fleksi siku disertai tekanan ekstensor lutut berkurang (Willson). Hal ini sesuai dengan penelitian Collins et al. (2003) bahwa langkah yang lebih lama memungkinkan otot-otot betis bisa rileks lebih lama dan, sehingga 
aliran darah akan lebih effisien menggunakan suplai darah yang terbatas secara lebih efisien dan mempunyai dampak responden lebih jauh jarak yang ditempuh.

Nordic Walkingmemiliki efek terbaik diikuti denganbrisk walkingyang memiliki peningkatan rata-rata ABPI masing-masing 8,4 $\mathrm{MHz}$ dan 0,65 MHz. Dengan demikian, parameter sirkulasi arteri perifer di kaki berubah seiring bertambahnya usia tetapi perubahan ditunjukkan dengan peningkatan pulsasi kaki dengan pemeriksaan ABPI pada pejalan kaki dengan menggunakan

Nordic Walking.Dibandingkan dengan latihan aktifitas lain, Nordic Walkingmemiliki efek terbaik diikuti oleh Brisk Walking.

\section{SIMPULAN}

PAD dapat dikendalikan dengan latihan yang terartur. Latihan dengan Nordic Walking dan Brisk Walking adalah intervensi lain yang dapat meningkatkan sirkulasi nadi dikaki pasien PAD. Latihan ini membantu mengurangi morbiditas dan mortalitas dari penyakit penyakit arteti perifer yang sekarang menduduki urutan teratas. Membandingkan kedua kegiatan tersebut, ditemukan bahwa peningkatan sirkulasi nadi kaki melalui pemeriksaan ABPI paling besar terjadi pada peserta yang berlatih Nordic Walking, diikuti peserta yang yang melakukan Brisk Walking. Namun, perlu dicatat bahwa kedua aktivitas tersebut juga mengurangi keluhan nyeri di kaki yang terbukti peserta bisa meningkatkan jarak tempuh saat berjalan. Kedua latihan tersebut adalah strategi yang lebih baik untuk mengelola kebugaran tubuh. Dengan demikian, ini menjadi bagian integral dari perawatan komplemeter dalam pencegahan PAD dan penyakit terkait dengan promosi kesehatan. Karena dapat dipraktikkan secara teratur, ini adalah alternatif pendekatan nonfarmakologis dan membantu individu untuk mengatasi PAD pada tahap awal yang mempromosikan perawatan komplementer.

\section{SARAN}

Latihan nordic walking dan brisk walking dapat diberikan pada pasien yang mengalami PAD. Karena latihan nordic walking menimbulkan perubahan denyut nadi kaki lebih besar dibandingkan latihan brisk walking maka nordic walking lebih disarankan diberikan pada pasien PAD untuk meningkatkan sirkulasi arteri kaki. Kemudian untuk penelitian selanjutnya disarankan agar mengembangkan penelitian dengan menghitung kemampuan peningkatan jumlah langkah dan jarak tempuh dari peserta.

\section{DAFTAR PUSTAKA}

Lingga, L. (2012). Bebas hipertensi tanpa obat. Jakarta: PT Agro Media Pustaka

Violi, F; Basili, S; Berger, JS; Hiatt, WR (2012). Terapi antiplatelet pada penyakit arteri perifer. Buku Pegangan Farmakologi Eksperimental 210 . hlm.54763. doi : 10.1007/978-3-64229423-5_22. ISBN 978-3-64229422-8 . PMID22918746.

Fowkes, FG, Rudan D, Aboyans V, Denenberg J O, McDermott M M, Norman, $P$ E, Sampson I, Williams L J, Mensah G A, Criqui M H (2013). Perbandingan perkiraan global prevalensi dan faktor risiko 
penyakit arteri perifer pada tahun 2000 dan 2010: Tinjauan dan analisis sistematis. Lancet . 382 (9901): 1329-40. doi : 10.1016/s01406736-61249-0

Rooke, T W, Hirsch, A T, Misra, S, Sidawy, AN, Beckman, JA, Findeiss, LK, Golzarian, J, Gornik, HL, Halperin, JL, Jaff, MR, Moneta, GL, Olin, JW, Stanley, JC, Putih, CJ, Putih, JV, Zierler, RE. (2011). Pembaharuan Berfokus ACCF/AHA 2011 dari pedoman 2005: Laporan dari American College of Cardiology

Foundation/American Heart Association Task Force on Practice Guidelines. Jurnal American College of Cardiology . 58 (19): 2020-45.

Gerhard-Herman, MD, Gornik, HL, Barrett, C, Barshes, NR, Corriere, MA. (2017). Panduan AHA / ACC 2016 tentang manajemen pasien dengan penyakit arteri perifer ekstremitas bawah: Ringkasan eksekutif: Laporan dari American College of Cardiology/American Heart Association Task Force on Clinical Practice Guidelines. Jurnal American College of Cardiology . 69 (11): $1465-$ 1508.

Shantulli, Shu (2018). Update tentang penyakit arteri perifer: Epidemiologi dan fakta berbasis bukti aterosklerosis. Jurnal American College of Cardiology . 58 (19):2020-45.

Willson J.Torry M.R.Decker M.J.Kernozek T.Steadman J.R. (2001). Effects of walking poles on lower extremity gait mechanics. Med Sci Sports Exerc. 33: 142-147

Fowkes FG, Housley E, Cawood EH, Macintyre CC, Ruckley CV, Prescott RJ.Edinburgh (1991). Artery study: prevalence of asymptomatic and symptomatic peripheral vascular disease in the general population. Int J Epidemiology. 20:384e92.

Gardner A.W., Poehlman E.T.(1995). Exercise rehabilitation programs for the treatment of claudication pain. A meta-analysis. JAMA 1995; 274: pp. 975-980.

Collins E.G.Edwin Langbein W.Orebaugh C.Bammert C.Hanson K.Reda D.et al.(2003). Polestriding exercise and vitamin $\mathrm{E}$ for management of peripheral vascular disease. Med Sci Sports Exerc. 35: 384-393

Hirsch AT, Haskal ZJ, Hertzer NR, Bakal CW, Creager MA, Halperin JL, et al. ACC/AHA (2005). Practice guidelines for the management of patients with peripheral arterial disease (lower extremity, renal, mesenteric, and abdominal aortic). Circulation 113(11):e463-5. (6)

Ratcliff D.A., Puttick M., Libertiny G., Hicks R.C., Earby L.E., Richards T.(2007). Supervised exercise training for intermittent claudication: lasting benefit at three years. Eur J Vasc Endovasc Surg 2007; 34: pp. 322-326.

Norgren L, Hiatt WR, Dormandy J a., Nehler MR, Harris $\mathrm{K}$ a., Fowkes FGR, et al.(2007). Inter society consensus for the 
management of peripheral arterial disease (TASC II). Int Angiol. 26(2):82-157

Blank, M.J. (2015). Building sustainable health and education partnerships: stories from local communities. Journal of School Health.Vol. 85 , No. 11, 235-250

Al-Qaisi, $\quad$ M; Nott, DM; Raja, DH; Kaddoura, tekanan (2009). Indeks brakialis pergelangan kaki (ABPI): Pembaruan untuk praktisi. Kesehatan Vaskular dan Manajemen Risiko. 5:83341

Gao L, Mann GE.(2009). Vascular $\mathrm{NAD}(\mathrm{P}) \mathrm{H}$ oxidase activation in diabetes: A double-edge sword in redox signaling. Cardiovascular Research. 82:9-20.

Mary M. McDermott, Kiang Liu, Luigi Ferrucci, Lu Tian, Jack M. Guralnik, Yihua Liao and Michael H. Criqui (2011). Journal of the American College of CardiologyV olume 57, Issue 23, June 2011DOI: 10.1016/j.jacc.2010. 12.038

Mikalački, M., Čokorilo, N., Katić, R. (2011). Effect of nordic walking on functional abilityand blood pressure in elderly women. Coll Antropol. Vol.35(3): 889-894.

Shim, J.M., Kwon, H.Y., Kim, H.R., Kim, B.I., Jung, J.H. (2013). Comparison of the effects of walking with and without nordic pole on upper extremity and lower extremity muscle activation. $J$ Phys Ther Sci. Vol. 25: 1553-1556
Aboyans, V., Criqui, M. H., Abraham, P., Allison, M. A., Creager, M. A., Diehm, C., ... Stoffers, H. E. J. (2012). measurement and interpretation of the ankle-brachial index a scientific statement from the american heart association rationale for standardization of the ABI. AHA Journal.

Kang, S.J., Kim, E.H., Ko, K.J. (2016). Effects of aerobic exercise on the resting heart rate, physical fitness, and arterial stiffness of female patients with metabolic syndrome. $J$ PhysTher Sci. Vol. 28: No. 6, 1764-1768.

Sandi, I.N. (2016). Pengaruh latihan fisik terhadap frekuensi denyut nadi. Sport and Fitness Journal. Vol. 4(2): 1-6.

Lew, E., Nicolosi, N., Botek, G. (2006). Elevated ankle brachial indices, incompressible arteries, and radiographic artery calcifications are prognostic indicators for lower extremity amputation. Diunduh dari https://www.eiseverywhere.co $\mathrm{m} /$ file 